\title{
A POESIA COMO CUIDADO DE SI: FORMAÇÃO E EDUCAÇÃO
}

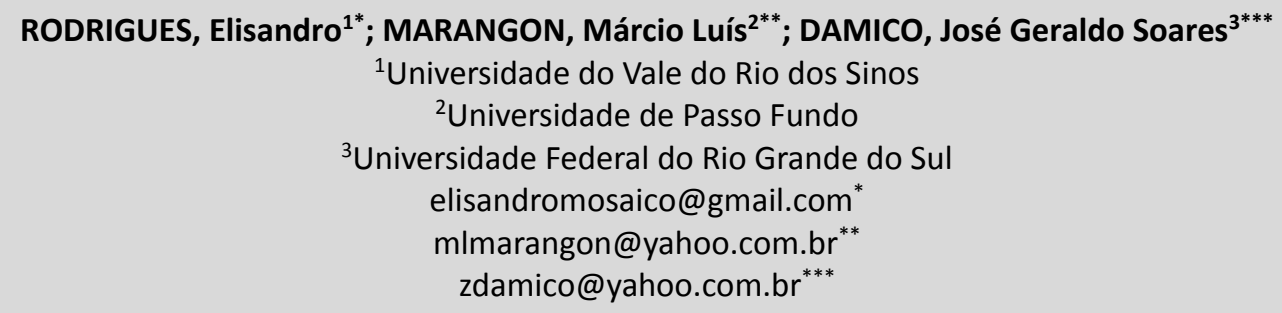

\section{RESUMO}

Articula-se neste artigo uma reflexão sobre a potência do pensamento e do cuidado de si, tendo por objetivo apresentar a poesia como instrumento de articulação, agenciada com experiências de trabalho no fazer educação em sala de aula. Escolhe-se, para ajudar neste processo, um suporte metodológico histórico-hermenêutico, com o qual se almeja dialogar e triangular autores e experiências pedagógicas. Para problematizar tal temática, divide-se o texto em três partes, sendo que na primeira se utilizará uma análise do papel da estética na Grécia antiga. Em um segundo momento, abordar-se-á o cuidado de si como alternativa para enfrentar as consequências dos modos de vida na sociedade contemporânea, e pressupostos de Foucault serão bases fundamentais para tais apontamentos. Por fim, há uma tentativa de montagem entre expressão poética e cuidado de si mediante experiências práticas desenvolvidas em zonas de aproximação entre a educação básica e a educação superior.

PALAVRAS-CHAVE: Poesia. Formação. Cuidado de si. Educação.

\section{POETRY AS SOME CARE OF THE SELF: EDUCATION AND EDUCATION}

\section{ABSTRACT}

This paper presents a reflection on the potency of thought and care of the self, aiming to present poetry as an instrument of articulation, articulated with work experiences in classroom teaching. In order to carry out this process, a historical-hermeneutical methodological support has been chosen, with which we aim to dialogue and intertwine authors and pedagogical experiences. Aiming at problematizing this thematic, the text has been divided into three parts. The first one analyzes the role of aesthetics in ancient Greece. The second approaches the care of the self as an alternative to face the consequences of ways of life in contemporary society, and Foucault's assumptions are fundamental for that purpose. Finally, we attempt to join poetical expression and care of the self by means of practical experiences developed in zones of approximation between basic education and higher education. KEYWORDS: Poetry. Education. Care of the Self. Education.

\section{LA POESÍA COMO CUIDADO DE SÍ: FORMACIÓN Y EDUCACIÓN}

\section{RESUMEN}

Se articula en este artículo una reflexión sobre la potencia del pensamiento y del cuidado de si por medio de la poesía, agenciada con la experiencia de trabajo en hacer educación en el aula. Se elige para ayudar en este proceso un soporte metodológico histórico-hermético, con el que se almeja dialogar autores y experiencias pedagógicas. Para la problematización de la temática, se divide el texto en tres partes, mientras que en la primera se utilizará un analice del papel de la estética en la Grecia Antigua. En un segundo rato, será abordado el cuidado de si como alternativa para enfrentar las consecuencias de los modos de vida en la sociedad contemporánea y algunas hipótesis de Foucault serán bases fundamentales para tales apuntes. Por fin, hay una tentativa de montaje entre la expresión poética y el cuidado de si a través de experiencias prácticas desarrolladas en zonas de aproximación entre la educación básica y la educación superior.

PALABRAS CLAVE: Poesía. Formación. Cuidado de sí. Educación. 


\section{PARA INICIAR NOSSA CONVERSA}

Articula-se neste artigo uma reflexão sobre a potência do pensamento e do cuidado de si por meio da poesia. Algo que brota pelo meio de experiências do trabalho com a poesia (visual) (BROSSA, 2005) no fazer educação em sala de aula. Trabalha-se aqui com a poesia como disparadora de uma política de si, que parte da necessidade de inventarmos outros modos de existência mediante a escrita e a leitura.

Para recordar, desde a Grécia antiga, a poesia - como expressão da arte e da literatura era desenvolvida como instrumento de expressão de si e do mundo. Como forma de expressão da arte, ajudava na tarefa de harmonizar os três estados da alma (a concupiscência, o irascível e a razão) e, por isso, era também vista como algo necessário para a formação do homem grego, como menciona Jaeger (1994).

Porém, a cultura ocidental contemporânea perdeu muito da preocupação com a formação integral do homem, primando por processos tecnicistas unilaterais. Isso gera a especificidade dos conteúdos e disciplinas escolares, estas focadas mais em conhecimentos técnicos do que em conhecimentos estéticos. Como resultado, percebe-se que tais condições de formação - às quais os indivíduos estão expostos na contemporaneidade - estabelecem uma sociedade emocionalmente desorientada, dado que não permitem aos indivíduos o autoconhecimento necessário para estabelecer parâmetros de equilíbrio interno e externo (HENZ; ROSSATO, 2007).

Ao contrário disso, assim como nos escritos de Goethe - principalmente em sua obra Os anos de aprendizado de Wilhelm Meister-, desafios de tamanha complexidade que se colocam na contemporaneidade necessitam de uma formação omnilateral e omnicompreensiva (MARANGON, 2016). Ou seja, uma formação que possibilite aos indivíduos a compreensão de si e do mundo, para que, preparados para uma leitura hermenêutica de si e de seu redor, possam potencializar atitudes regenerativas de vida em todas as suas esferas.

Na busca por caminhos que levem os indivíduos até esse processo formativo, é possível lembrar que Foucault (2004) fala da necessidade de criar-se no que se escreve, indicando com isso que a leitura e o trabalho com a poesia podem ser vistos como um exercício de si passível de potencialização do pensamento e da vida. É algo que aponta para a necessidade de desenvolver experiências e exercícios que visam a proporcionar linhas de fuga aos sujeitos e às 
subjetividades, estabelecendo condições de cuidado de si e afirmação do "em-si" e da sensibilidade do individual para o coletivo e do coletivo para o individual. Assim, mostra-se inevitável promover espaços de formação e expressão estética, e, para isso, a poesia coloca-se como uma alternativa passível de atenção.

Acreditando nisso, este artigo busca acompanhar os anseios por uma educação mais estética e possibilitadora de cuidado de si, que contribua ao enfrentamento das formas uniformes e dogmáticas de educação e que aponte caminhos mais hermenêuticos de si e do mundo, de modo a proporcionar alternativas de cuidado na formação dos sujeitos e, consequentemente, de um mundo melhor.

Para problematizar tal temática, dividimos este artigo em três partes. Na primeira parte, faz-se uma análise do papel da estética na Grécia antiga e de como, por meio da poesia e dos poetas, ela é tão importante para desenvolver os indivíduos e torná-los mais conscientes de si. Ao mesmo tempo, também se considera como a sociedade complexa contemporânea diminui os espaços de formação estética e parece esquecer-se de todos os benefícios vislumbrados na Grécia antiga.

Em um segundo momento, o texto aborda a importância de vislumbrar o cuidado de si como alternativa para enfrentar as consequências da sociedade complexa contemporânea; para isso, os pressupostos de Foucault serão bases fundamentais. Por fim, a última parte do texto constitui uma tentativa de agenciamento entre expressão poética e cuidado de si mediante experiências práticas desenvolvidas em zonas de aproximação entre a educação básica e a educação superior. Para dar conta de todo esse processo, escolheu-se um suporte metodológico histórico-hermenêutico, com o qual se almeja dialogar e triangular autores e experiências pedagógicas.

\section{A FORMAÇÃO GREGA POR MEIO DA POESIA}

A Grécia antiga tinha algo de peculiar em relação à educação: tinha como concepção levar os indivíduos a imitarem os grandes modelos - sobretudo os modelos dos heróis -, mimeticamente descritos como expressão das virtudes. Tais virtudes seriam essenciais para a constituição de bons indivíduos e, consequentemente, para a constituição de uma boa sociedade. Assim sendo, para que fosse possível que os indivíduos - principalmente os jovens - seguissem os 
conceitos de virtude dos heróis, os poetas desempenhavam papel importantíssimo na educação grega, bem como na própria sociedade.

Para vislumbrar tal questão, basta recuperar a importância da gramática e da retórica e as riquezas éticas e estéticas trazidas nos dois principais poemas da época, Ilíada e Odisseia, em que os personagens principais serviam como verdadeiros "moldes" para a reflexão da biografia de cada indivíduo, compondo os aspectos necessários para desenvolver o que os gregos denominavam de psicagogia:

[...] A evocação do exemplo dos heróis famosos e do exemplo das sagas é para o poeta parte constitutiva de toda a ética e educação aristocráticas. Temos de insistir no valor deste fato para o conhecimento essencial dos poemas épicos e da sua radicação na estrutura da sociedade arcaica. Mas até para os Gregos dos séculos posteriores os paradigmas têm o seu significado como categoria fundamental da vida e do pensamento. (JAEGER, 1994, p. 59).

Dessa maneira, caracteriza-se a importância do poeta e da poesia para a formação do povo grego, algo que ia além dos aportes pedagógicos, bem como além da própria geração que presenciou a construção desses poemas e que reverenciou os trabalhos daqueles poetas:

[...] a importância educadora de Homero é evidentemente mais vasta. Não se limita à formulação expressa de problemas pedagógicos nem a algumas passagens que aspirem a produzir um determinado efeito moral. A poesia homérica é uma vasta e complexa obra do espírito, que não se pode reduzir a uma fórmula única. Ao lado de fragmentos relativamente recentes que revelam um interesse pedagógico expresso, aparecem outras passagens nas quais o interesse pelos objetos descritos afasta a possibilidade de pensar uma segunda intenção moral do poeta. (JAEGER, 1994, p. 66).

Outro fator importante a se referir é a reflexão trazida por Havelock (1996). Conforme esse pensador, muitas poesias (como llíada ou Odisseia, de Homero) foram criadas por meio da oralidade (como poesia cantada), somente sendo imortalizadas mediante a escrita anos mais tarde, visto que tinham como objetivo a preservação do ethos e a exaltação das virtudes do povo por um método didático.

Nesse caso, mostra-se a preocupação dos poetas/educadores de, em meio a uma sociedade "iletrada" (poucos tinham acesso ao saber na Grécia antiga), desenvolver uma forma de trabalhar condutas e normas desejadas para a sociedade, algo que fosse um mero discurso vazio, que seria facilmente esquecido pelos indivíduos, mas que, ao ser cantarolado de geração em geração, com o poder da imaginação, pudesse desenvolver possibilidades de reflexão para o 
povo e, consequentemente, mesmo que de forma superficial, sua formação, como é possível ver na Elegia de Calino de Éfeso ${ }^{1}$ :

\author{
Até que ponto, inertes, folgareis? \\ Vergonha não vos dá dos que na luta \\ A pátria amparam, ou quereis, talvez \\ A paz, quando os demais no ardor se ralam? \\ Mesmo a morrer, a lança arremessai, \\ Também na morte é que se ganha a glória, \\ E salva é a esposa, o filho, e seus pais. \\ Ah, perecer, por eles, é vitória! [...].
}

Também, de forma evidente, é possível perceber a importância da poesia nas obras de Platão e Aristóteles. O primeiro dedica parte de sua República a exclamar o valor dos poetas e da poesia, principalmente no capítulo dez, onde, fazendo referência a um poeta, demonstra que os indivíduos têm muito a aprender com este no que concerne tanto à administração, quanto à educação dos assuntos humanos (PLATÃO, 2008).

Já o segundo dedica uma obra inteira para demonstrar o apreço pela poesia - trata-se de sua Poética. Aliás, em se tratando da Poética de Aristóteles, é imprescindível não fazer uma reflexão mais contundente dessa obra em relação à poesia, visto que Aristóteles a apresenta não somente como uma forma educativa, mas também como uma forma educativa pela reflexão sobre a própria vida: é a arte mimética - algo que fica claro na sétima estrofe do capítulo VI (ARISTÓTELES, 1966, p. 40):

\begin{abstract}
Como a imitação se aplica a uma ação e a ação supõe personagens que agem, é de todo modo necessário que estas personagens existam pelo caráter e pelo pensamento (pois é segundo estas diferenças de caráter e de pensamento que falamos da natureza dos seus atos); daí resulta, naturalmente, serem duas as causas que decidem dos atos: o pensamento e o caráter; e, de acordo com estas condições, o fim é alcançado ou malogra-se.
\end{abstract}

Ora, ao demonstrar que a imitação se aplica sobre a "ação das personagens" e que é essa imitação que leva os indivíduos a refletirem sobre o pensamento e o caráter, Aristóteles demonstra que a poesia é mais do que uma simples forma de escrita - é, sim, uma possibilidade de reflexão pela ação, ou ainda, uma reflexão sobre a ação dos indivíduos, com a vantagem de que, enquanto o texto literário comum se coloca em si e por si, a poesia possibilita uma expansão sobre a leitura de cada indivíduo.

1 Tradução disponível em: <http://primeiros-escritos.blogspot.com.br/2007/09/calino-e-tirteu.html>.

Educação \& Formação, Fortaleza, v. 3, n. 7, p. 85-103, jan./abr. 2018

DOI: http://dx.doi.org/

http://seer.uece.br/redufor 
Assim, a poesia coloca-se desde a Grécia antiga como algo potencialmente formador, importante para a Paideia e inspiradora de outras formas de escrita que viriam no decorrer da história da humanidade, bem como de outros autores e modelos de formação, como, por exemplo, Goethe e seus escritos, que representaram tão bem a Bildung ${ }^{2}$ na Alemanha dos séculos XVIII e XIX. A poesia posiciona-se como potencializadora do cuidado de si e do mundo pela prática de um cuidado de si por meio da escrita. O indivíduo, ao representar o que sente e o que vive de maneira simbólica, pode criar um molde a ser repetido e imitado (de mimesis), ou não, pelas próximas gerações e por si mesmo, sendo fonte de recriação e aprimoramento de sua existência.

Porém, em tempos modernos, em que a gramatização e a digitalização ${ }^{3}$ do mundo se tornaram as principais fontes de registro e transmissão cultural, a poesia e a própria constituição estética - no sentido de sentimento de mundo, e não apenas de mercantilização - perderam espaço na sociedade. Também outras formas miméticas de formação, como o próprio teatro, perderam espaço em meio à cultura de massa, sendo substituídas por filmes e telenovelas, os quais captam o povo pela projeção e representação idealizadora dos conceitos capitalistas do mundo.

Para pensadores como Adorno e Horkheimer, a revolução industrial e principalmente a ascensão da burguesia ao poder - com seus ideais de semiformação (Halbbildung ${ }^{4}$ ) constituíram uma cultura de massa que não busca a formação dos indivíduos, mas sim sua alienação. Um dos exemplos de tal "aparelhagem" está nos programas de televisão da atualidade, principalmente no que se refere às telenovelas. Para Marcondes Filho (1988), apesar de estar há muito pouco tempo no meio das pessoas (em se comparando com outras artes e aparelhos), a televisão "atende" às necessidades humanas. Ela cria a possibilidade de fantasiar situações necessárias ao dia a dia do homem, dando-Ihe a possibilidade de viver uma vida dupla: de um lado, seu mundo real, onde se encontram as atividades do trabalho, dos estudos, das normas,

2 Modelo de formação cultural surgido no séc. XVIII, considerado a Paideia da Alemanha.

3 Refere-se aqui a duas épocas distintas e suas formas de registrar e arquivar do mundo para as futuras gerações: a primeira relaciona-se ao modo de escrita em que o mundo passou a ser "gramatizado", ou seja, escrito e descrito para sua transmissão às futuras gerações, substituindo as artes rupestres e a transmissão oral, que usava como meio as poesias e os contos. A segunda diz respeito à modernidade e às suas novas formas de registrar e arquivar o mundo de maneira digital, em que o mundo é registrado a todo o momento em forma de imagens, seja por foto, seja em filmes, ocasionando uma digitalização do mundo, a qual, aos poucos, substitui a forma escrita de registro.

4 Adorno faz duras críticas à burguesia Alemã do século XVIII, apontando que fizeram da Bildung - formação cultural e omnilateral - um ideal de formação técnica e unilateral, transformando então em Halbbildung, ou, formação pela metade - semiformação.

Educação \& Formação, Fortaleza, v. 3, n. 7, p. 85-103, jan./abr. 2018

DOI: http://dx.doi.org/

http://seer.uece.br/redufor 
etc.; de outro, há um segundo mundo, onde se encaixa a televisão - o mundo das fantasias e situações irreais, que distraem e (des)informam as pessoas:

\begin{abstract}
Diante de uma vida problemática e sem esperanças, da necessidade de ganhar dinheiro, de ter uma casa ou um negócio próprio, de encontrar um companheiro, diante das exigências do trabalho, das contas a pagar e dos compromissos, a esfera emotiva das pessoas retrai-se. A vida que a televisão mostra é então, para o homem e para a mulher, uma verdadeira troca, com vantagens, de sua vida real. (MARCONDES FILHO, 1988, p. 60).
\end{abstract}

Em uma comparação, enquanto a poética aristotélica buscava desenvolver e aprofundar nos indivíduos a necessidade das artes miméticas, voltadas para a reflexão e para a expressão ativa de cada um - cada um expressando e tornando-se transmissor de uma cultura rica em ethos por intermédio da oralidade das poesias, das tragédias e das comédias -, o mundo moderno desenvolveu o que Platão (2008) tanto temia em seu Mito da caverna: a ilusão, a fuga do real, a falta de reflexão e de conhecimento de si e do mundo. Ou seja, enquanto a poesia grega projetava o ethos do mundo ideal, na contemporaneidade, a televisão projeta um ethos do capitalismo ideal. Dessa forma, a sociedade contemporânea em sua formação de massa, ou semiformação, parece esquecer, não compreender, ou ainda, não conhecer as vantagens da formação humana por meio de expressões estéticas e miméticas, tendo como exemplo clássico o potencial da poesia e sua capacitação de expressão de mundo, potencialização da compreensão deste e do ethos e das virtudes humanas.

\title{
3 BREVES CONSIDERAÇÕES SOBRE O CUIDADO DE SI EM FOUCAULT
}

A situação apresentada nesta primeira parte do trabalho evidencia a necessidade de constituir novas formas de educar, bem como de recuperar maneiras de educar os indivíduos, tendo como parâmetro os grandes avanços culturais da humanidade, para que a sociedade possa ser conduzida novamente para um caminho de vida mais tranquila e equilibrada, consigo mesma e com o mundo. Diante de tal perspectiva, é possível apontar inúmeros autores: Platão, Aristóteles, Goethe, Schiller e tantos outros que procuraram equilibrar vida e mundo, ética e estética, ser e parecer. Contudo, neste momento, somos também "tentados" a olhar um autor que se serviu de todos esses para a constituição de sua teoria: trata-se de Michel Foucault.

Educação \& Formação, Fortaleza, v. 3, n. 7, p. 85-103, jan./abr. 2018

DOI: http://dx.doi.org/

http://seer.uece.br/redufor 
Para recordarmos o pensamento de Michel Foucault, bastante estudado pelo campo da educação, situam-se três momentos em sua produção teórica, em sua dedicação ao tema: a) dos campos de saberes, b) das relações de poder e c) das relações consigo mesmo (GALLO, 2006). Veiga-Neto (2014) utiliza a sistematização proposta por Miguel Morey (1990) para diferenciar a ontologia e os domínios foucaultianos:

[...] pelo saber (ser-saber), pela ação de uns sobre os outros (ser-poder) e pela ação de cada um consigo próprio (ser-consigo). Ou, se quisermos, como nos constituímos como sujeitos do conhecimento, como sujeitos de ação sobre os outros e como sujeitos de ação moral sobre nós mesmos. (VEIGA-NETO, 2014, p. 40).

Interessa-nos aqui o terceiro movimento do pensamento foucaultiano, o ser-consigo, em que o autor irá escrever sobre a ética, a moral e o cuidado de si, ou seja, as "tecnologías del yo". Foucault chega a essa problemática da ética, do ser-consigo, das relações do sujeito consigo mesmo, "quando investiga os jogos de poder que produziram e produzem nossos saberes sobre a sexualidade" (GALLO, 2006, p. 179). Para isso, busca a noção de cuidado de si nos textos gregos e romanos (Sócrates, Alcebíades, Epicuro, Sêneca, Marco Aurélio, Plínio, Epicteto), principalmente os epicuristas e estoicos: "O que se marca nos textos dos primeiros séculos é a insistência sobre a atenção que convém para consigo mesmo... é a importância de se respeitar a si mesmo, não simplesmente em seu próprio status, mas em seu próprio racional" (FOUCAULT, 1985, p. 46-47).

A produção sobre o cuidado de si ancora-se principalmente nos últimos textos e cursos da obra de Foucault: os cursos "Subjetividade e verdade", de 1980-1981, e "Hermenêutica do sujeito", de 1981-1982, continuando nos livros História da sexualidade (volume 2 e 3), publicados em 1984, Os usos dos prazeres e O cuidado de si.

Foucault problematiza a relação do ser-consigo a partir de práticas, técnicas e tecnologias de si/do eu, como uma ética do eu: "o sujeito suposto por essas técnicas de si, pelas artes da existência é um eu ético, antes que um sujeito ideal de conhecimento" (GROS, 2008, p. 127). As práticas de si referem-se às formas e modos de atividades dos sujeitos sobre si mesmos, ou seja, a relação consigo mesmo, como o sujeito se constitui em determinados modos de vida, dados por condições de possibilidade existentes. As práticas constituem uma experiência de si, sendo sistemáticas e recorrentes na vida do sujeito. Para Foucault (2004, p. 244), "as práticas de si assumem a forma de uma arte de si". As técnicas de si são os modos de colocar em 
funcionamento as práticas, ou seja, os modos de análise e reflexão para o desenvolvimento regular de uma determinada prática. Pode-se também considerar as técnicas de si como exercício de si "sobre si mesmo através do qual se procura elaborar, se transformar e atingir um certo modo de ser" (FOUCAULT, 2004, p. 259).

Foucault, nos seus textos sobre o cuidado de si, faz uma diferenciação, uma oposição de dois princípios morais: o "ocupar-se de si mesmo", "tomar conta de si", "ter cuidado consigo" (epimeleisthai sautou/epimeleia heautou) e o "conhecer-se a si mesmo" (gnôthi seauton) (FOUCAULT, 1985, 1990; GALLO, 2006; GROS, 2008; REVEL, 2005; SCHULER, 2014; VEIGA-NETO, 2014).

Schuler (2014, p. 78) comenta que Foucault busca o conceito de cuidado de si "na antiguidade grega e romana e o deslocamento ocorrido do cuidado para o conhecimento de si, ainda com os atravessamentos platônicos para a lógica pastoral cristã e a perspectiva cartesiana". Tem-se, dessa forma, três deslocamentos do conceito - o primeiro, socrático-platônico; o segundo, helenístico-romano; e o terceiro, cartesiano (GALLO, 2006; SCHULER, 2014).

Para os gregos, o cuidado de si era um dos grandes princípios que regiam a ocupação com o governo das cidades e o governo de si, um dos fundamentos da arte de viver. Para Foucault (1990), essa noção perdeu potência, e sua força tornou-se obscura, esquecendo-se o ocupar-se de si pelo princípio délfico "conhece-te a ti mesmo" (gnôthi seauton). Ocupar-se de si implica um labor, um trabalho sobre si constante; por isso, antes de conhecer-se a si, necessita-se ocupar-se de si, ou seja, na cultura grego-romana, o conhecimento de si é uma consequência do cuidado de si: "[...] esto ha estado implícito en toda la cultura griega y romana [...] uno tenía que preocuparse de sí mismo. Tenía que ocuparse uno mismo de sí mismo antes de que el principio délfico fuera puesto en práctica. Se produjo una subordinación del segundo principio al primero" (FOUCAULT, 1990, p. 51).

No primeiro período, socrático-platônico, o cuidado de si era a preparação inicial para o cuidado com a cidade, para o governo dos outros. Dessa forma, o cuidado de si estava vinculado, e havia uma "submissão da ética à política" (GALLO, 2006, p. 183). Foucault toma como base de seus estudos a relação entre Sócrates e Alcebíades.

No período helenístico-romano, ocorre uma transição; o cuidado de si é tomado como uma forma de arte de viver, como um tema filosófico comum, sendo reconhecido pelos filósofos. Nesse período, a escrita mostra-se importante para os exercícios e exames: "escribir también era importante en la cultura del cuidado de sí. Una de las características más importantes de este 
cuidado implicaba tomar notas sobre sí mismo" (FOUCAULT, 1990, p. 62). A escrita das cartas era comum como exercício de si, e as cartas de Sêneca são um exemplo dessa escrita. Com isso, o cuidado de si passa a ser uma atividade constante por meio da escrita. O cuidado de si afasta-se da política, é colocado acima, como tema filosófico, ou seja, deve-se afastar da vida política para melhor cuidar de si (FOUCAULT, 1985, 1990; GALLO, 2006).

Algumas práticas e técnicas podem ser citadas. Faz-se importante ressaltar que elas foram mudando de função dos estoicos para o cristianismo; por exemplo, na filosofia estoica ${ }^{5}$, há a escrita de cartas aos amigos. O exame de si e askêsisi dão-se não como revelação de si, mas como um modo de rememoração do vivido, um processo de conhecer mais o mundo e a realidade em que se vive: "tiene su meta final no en la preparación para otra realidad sino en el acceso a la realidad de este mundo" (FOUCAULT, 1990, p. 73-74).

Há um deslocamento com a tradição cristã, ou melhor, com a moral cristã ocidental, em que houve uma transformação nos modos de pensar e de viver a vida. As técnicas citadas acima deslocam os sentidos para a confissão, a obediência e a contemplação religiosa, para uma salvação de si. Os exercícios e práticas passam a reger e controlar a vida. Foucault $(1985$, p. 48) destaca três principais deslocamentos que ocorreram nesse período: a) uma atitude individualista frente ao mundo e às pessoas; b) uma valorização da vida privada; c) a intensidade das relações consigo mesmo, "isto é, das formas nas quais se é chamado a se tornar a si próprio como objeto de conhecimento". Na moral cristã, renunciar a si é um meio de alcançar a salvação, uma forma de ascese, e conhecer-se a si mesmo é um dos modos de renunciar a si mesmo. No mundo moderno e contemporâneo, cartesiano, o conhecimento de si, o "penso, logo existo", tornou-se o princípio fundamental, muito centrado ainda em exercícios e práticas cristãs, valorizando a vida privada, o individualismo e o conhecimento - razão, saber.

É importante essa breve contextualização para dizer que o conceito de cuidado de si, problematizado por Foucault, é operado principalmente com a identificação da filosofia helenística e romana, no primeiro momento, antes de deslocar-se para uma moral cristã. Gros (2008, p. 132), em sua reflexão sobre o presente conceito, traz duas contribuições importantes. Primeiramente, pensando no distanciamento, diz ele que "Foucault mostra claramente que o cuidado de si introduz

5 Escola filosófica fundada por Zenão de Citio - que teve também como grandes representantes Sêneca, Epiteto e Marco Aurélio - que tinha como princípio exaltar as virtudes por meio da busca pela retidão da vontade e do afastamento dos vícios.

Educação \& Formação, Fortaleza, v. 3, n. 7, p. 85-103, jan./abr. 2018

DOI: http://dx.doi.org/

http://seer.uece.br/redufor 
entre o sujeito e o mundo uma certa distância, mas esta distância é precisamente constitutiva da ação". A segunda contribuição seria a de pensar o cuidado de si como uma ação política, e não nos afastamos da política como no período cristão e moderno/contemporâneo. Somos sujeitos de ação - ao cuidarmos de nós mesmos e ao cuidarmos da cidade, somos sujeitos de ação política. Essa distância permite uma ação política de cuidado de si e do mundo, ou seja, "não se cuida de si para escapar do mundo, mas para agir como se deve" (GROS, 2008, p. 132).

Trabalhando com a ideia de cuidado de si, da filosofia helenística e romana dos epicuristas ${ }^{6}$ e estoicos, pode-se dizer que cuidado de si é um "trabalho de pensamento" (FOUCAULT, 1985, p.67), como arte da existência, um conjunto de experiências, técnicas e práticas mediante exercícios que o sujeito desenvolve para a transformação de si; trata-se de "uma intensificação da relação consigo pela qual o sujeito se constitui enquanto sujeito de seus atos" (FOUCAULT, 1985, p. 47). Cuidado de si como "uma maneira de se relacionar consigo mesmo para se construir, para se elaborar" (GROS, 2008, p. 128), corresponde, nesta concepção, a um eu ético, ou seja, a "fazer da vida um objeto de tekhnê, uma obra de arte" (REVEL, 2005, p. 33-34).

Foucault (1985, p. 50) explica que a expressão cuidado de si ganhou diferentes formas de compreensão tendo um alcance bastante geral, podemos perceber:

\begin{abstract}
[...] o preceito segundo o qual convém ocupar-se consigo mesmo é em todo caso um imperativo que circula entre numerosas doutrinas diferentes; ele também tomou a forma de atitude, de uma maneira de se comportar, impregnou formas de viver; desenvolveu-se em procedimentos, em práticas e em receitas que eram refletidas, desenvolvidas, aperfeiçoadas e ensinadas; ele constituiu assim uma prática social, dando lugar a relações interindividuais, a trocas e comunicações e até mesmo a instituições; ele proporcionou, enfim, um certo modo de conhecimento e elaboração do saber.
\end{abstract}

Ocupar-se de si concebido como um modo de vida ético deve ser compreendido, então:

[...] como uma modificação de atividade: não é que se necessite interromper qualquer outra forma de ocupação para consagrar-se inteira e exclusivamente a si, mas, nas atividades que é preciso ter, convém manter em mente que o fim principal a ser proposto para si próprio deve ser buscado no próprio sujeito, na relação de si para consigo. (FOUCAULT, 1985, p. 69).

6 Sistema filosófico fundado por Epicuro de Samos, o qual pregava a moderação dos prazeres para atingir a tranquilidade e a ausência de sofrimento corporal pelo conhecimento e aceitação do funcionamento do mundo e das limitações dos desejos humanos.

Educação \& Formação, Fortaleza, v. 3, n. 7, p. 85-103, jan./abr. 2018

DOI: http://dx.doi.org/

http://seer.uece.br/redufor 
As práticas de si, de cuidado de si, não constituem um conceito homogêneo, como observamos, tomado como um princípio básico de vida. O cuidado de si refere-se "a uma noção bastante complexa, que diz respeito, a um só tempo, a uma atitude, a uma forma de atenção e a um princípio de movimento (na qualidade de transformação)" (MARCELLO; FISCHER, 2014, p. 161).

Dado isso, chegamos neste ponto a uma encruzilhada onde, de um lado, se tem - a partir dos estudos de Foucault - a certeza sobre a necessidade do cuidado de si; mas, de outro, há a semiformação (Halbbildung), uma cultura de massa que não busca a formação dos indivíduos, mas sua alienação. Diante de tal paradoxo, fica evidente a necessidade de fazer algumas perguntas: como recuperar nos indivíduos uma formação voltada à sua omnicompreensividade ${ }^{7}$ ? Quais seriam os caminhos para constituir uma educação que potencializasse o cuidado de si? Seria isso possível na sociedade contemporânea?

É indiscutível que tais questionamentos se colocam como um desafio a qualquer educador da contemporaneidade. Da mesma forma, seria até mesmo um tanto ignorante pensar em uma solução definitiva, revolucionária, para tal problema. Entretanto, isso não significa que constantes tentativas de constituição de uma educação melhor não sejam possíveis e necessárias.

Considerando isso, a partir do que foi elaborado até o momento, pensamos que seja possível vislumbrar alguns lampejos (DIDI-HUBERMAN, 2011) ante as próprias reflexões aqui apresentadas. Por exemplo: o problema apresentado relaciona-se com a dificuldade dos indivíduos de conhecerem a si mesmos e aquilo que está ao seu redor; com isso, suas atitudes cotidianas tornam-se equivocadas, prejudicando a si, aos outros e ao mundo.

Por outro lado, recuperando as pesquisas de Foucault, é possível recordar que, principalmente até o período helenístico-romano, uma das características da formação eram as técnicas de conhecimento de si. E aí, é possível recuperar neste momento a poesia e o teatro grego como exemplos e as "notas de si" do período helenístico-romano.

Ora, ambas as técnicas parecem confluir: a escrita de si pode tornar-se poesia e teatro! E eis, então, que parece apresentar-se à formação contemporânea a técnica da escrita como possibilidade de formação omnicompreensiva. Para reforçar tal tese, na última parte deste artigo, aborda-se a ideia da poesia como um caminho e uma possibilidade de escrita e conhecimento de

7 Processo de autocompreensão integral.

Educação \& Formação, Fortaleza, v. 3, n. 7, p. 85-103, jan./abr. 2018

DOI: http://dx.doi.org/

http://seer.uece.br/redufor 
si. A ideia é partir de exemplos concretos de trabalhos formativos para ampliar a discussão sobre o tema e possibilitar uma reflexão com experiências em sala de aula.

\section{A POESIA COMO INSTRUMENTO DE RECUPERAÇÃO DO CUIDADO DE SI}

Conforme Foucault (2013), a poesia, como forma de expressão estética de uma experiência do interior, coloca-se como estratégia para o pensamento, em um escrever e descrever a si e ao mundo, tendo-se com isso a condição de ver e ver-se em outro olhar, na criação de imagens que escapam por frestas, por entre linhas. Contrapondo tal reflexão com o que foi apresentado acima sobre a crise de formação na sociedade contemporânea - complexa, célere e plural -, que expõe a necessidade de uma formação que leve os indivíduos a desenvolver-se de maneira omnicompreensiva, é possível perceber que a escrita, por meio da poesia, se coloca como uma excelente técnica que vai de encontro aos problemas causados pela semiformação e ao encontro da almejada formação omnicompreensiva.

Como exemplo de tal abrangência da técnica de poesia, é possível observar o desenvolvimento do Projeto Zonas Entre Nós. Tal projeto proporcionou uma troca de cartas e de poemas objetos ${ }^{8}$ entre alunos das licenciaturas de uma universidade pública e alunos de uma escola municipal da região metropolitana de Porto Alegre. Por meio de oficinaulas (RODRIGUES; GAI, 2015) ${ }^{9}$, procurou-se criar zonas de contato entre o ambiente universitário e escolar, entre estudantes de licenciatura e estudantes do ensino fundamental. Em experiências de produção de materiais, procurou-se criar zonas de contato entre o ambiente universitário e a escola. Para isso, utilizaram-se alguns dispositivos artísticos, dentre estes, a obra do artista catalão Joan Brossa (1919-1998), que desenvolveu uma obra plural e extremamente política.

8 Poemas objetos é uma definição utilizada por Jorge Brossa para pensar a montagem e o agenciamento da poesia com objetos do cotidiano.

9 Os autores utilizam o termo realizando uma colagem e uma variação com os termos oficinas e aulas, produzindo dessa forma a palavra oficinaulas. É um "entre que funciona na produção de conhecimento e aprendizagem, como na construção da vida como obra de arte. As oficinaulas se prestam à criação de instrumentos, de dispositivos, de ferramentas para o trabalho com crianças e adolescentes, jovens e adultos. As oficinaulas versam sobre escola, aula, planos diversificados, inventos inclusivos, atividades compartilhadas, docência compartilhada, ludicidade, riso, contemporaneidade na vida e na escola. Em grande medida as oficinaulas tratam da diferença, da pessoa com deficiência, daquele que vive em fuga, por linhas de fuga" (RODRIGUES; GAI, 2015, p. 3).

Educação \& Formação, Fortaleza, v. 3, n. 7, p. 85-103, jan./abr. 2018

DOI: http://dx.doi.org/

http://seer.uece.br/redufor 
Esse projeto buscou instigar a troca de experiências, sensações e impressões sobre a escola e a docência.

Do artista Joan Brossa, retirou-se a ideia de "Poema Transitável", "Poema Objeto" e "Poema Visual", em que os objetos cotidianos, colocados em trânsito, se tornam eles mesmos matéria de poesia. Partindo de algumas experimentações de contrassensos de sentidos, da utilização da poesia e dos corpos, compartilhou-se uma forma de criação e cuidado de si. Algumas questões provocaram o pensamento nesse agenciamento de cartas e poemas objetos: como se realiza uma troca de experiências, sensações e impressões entre alunos do ensino superior e da educação básica? O que pode um corpo quando tocado pelo cuidado? O que brota no intervalo de tempo do sentir o outro? Quais são os hiatos de cuidado num instante qualquer, quando vaza um pormenor de cuidado?

No decorrer de dois semestres, os alunos de graduação e do ensino fundamental realizaram esse intercâmbio. Para essas artistagens, os alunos do ensino superior e da escola municipal tiveram que dar outro sentido aos objetos cotidianos. Tiveram que criar. Tiveram que pensar:

\footnotetext{
Pensar é experimentar, é problematizar [...]; pensar é ver, é falar, mas pensar faz-se no entremeio, no interstício [...]; é inventar sempre o entrelaçamento, lançar sempre uma flecha de um contra o alvo dos outros, fazer brilhar um clarão de luz nas palavras, fazer ouvir um grito nas coisas visíveis [...]; pensar é emitir singularidades, é lançar os dados. (DELEUZE, 2005, p. 158).
}

Antes das zonas de aproximação por meio das cartas e dos poemas objetos, fez-se um estudo sobre a vida e a obra de Joan Brossa. Esse estudo, realizado nesses dois pontos diferentes da educação, possibilitou muitos encontros, desenvolvendo uma conexão, uma Zona que aproximou três mundos: o do poeta, o dos alunos do ensino superior e o dos alunos da escola municipal.

Joan Brossa nasceu em Barcelona, em 1919, e faleceu em 1998. Ao longo de toda a sua vida, dedicou-se às experimentações - sua vida era uma experimentação. Dizia que mostrava o que sentia por intermédio da poesia. Sempre esteve em movimento, compondo uma obra plástica e poética que passava nos espaços "entre", nas zonas, pela poesia visual; poesia em verso; poesia objeto; instalações; poemas transitáveis (esculturas-poema em locais públicos), poemas cênicos (textos para teatro) e roteiros cinematográficos. Brossa era em si uma zona. Era uma mistura de mágico com performer, poeta, ativista, artista gráfico e artista plástico. 
Sobre seu processo de criação, ele fala:

\begin{abstract}
Foi todo um processo. Eu comecei fazendo literatura com peruca, depois me concentrei na linguagem coloquial e depois passei ao objeto. Para mim a escrita e o trabalho com os objetos são ferramentas que me permitem colher a poesia, que como a eletricidade está em todas as partes, tem é que colhê-la. O poeta constrói pequenos veículos para transmitir a poesia. Duchamp encontrava uma coisa e a deixava assim. Eu gosto de alterar os objetos e fazer metáforas. Eu colho um fragmento da realidade mais comum, uma propaganda de um periódico, por exemplo, e gosto de tocá-lo um pouco, intervindo minimamente. Os objetos têm um sentido, eu o pego do cotidiano e lhe dou outro sentido, tratando de resgatá-lo dessa dependência funcional. (BROSSA apud TERÇA-NADA, 2003, p. 3).
\end{abstract}

Posteriormente a essa introdução ao pensamento de Brossa, foram realizadas trocas de cartas. Primeiramente, os estudantes de licenciatura encaminharam uma carta, sendo respondida pelos estudantes do ensino fundamental. Em resposta a essas cartas, foram produzidos poemas objetos, realizando-se uma segunda troca.

Preciosa (2010, p. 75) fala-nos que "invenção é intervenção na existência movida por uma profunda necessidade. É construir uma câmara de ecos, que ressoe o vivo e você junto. Inventar não é colorir o mundo, mas corar-se de mundos". Coramos mundos quando propomos que essas duas zonas distintas e diferentes se mostrem em silhuetas de sentidos, em zonas de invenção, em processos de cuidado de si, utilizando a poesia.

Nesse jogo poético de palavras e objetos, muitos são os sentidos construídos nesse Projeto. Muitas são as invenções e as intervenções nas vidas e nos modos de viver. Como nos diria Brossa (2005, p. 43): "La poesia és un joc on, sota una realitat aparent, hi apareix una"10.

São contrassensos que brotam, são descobertas, aproximações que fazem "passar por todos os domínios sensíveis, por todos os níveis de sensações diferentes" (DELEUZE, 2007, p. 1819). Propomos um jogo de encontro entre zonas em que uma poética do cuidado brota. Um olhar diferente é lançado para esse outro que nos é estranho. Um compartilhar de sentidos e sensações com alguém desconhecido - "trata-se de colocar em foco aquela outra metade do mesmo mundo que é feita, essencialmente, de movimentos, de devires e de transformações" (TADEU; CORRAZA; ZORDAN, 2004, p. 133), de sentidos.

Partilhamos sentidos com cartas, com poemas objetos, com corpos que, mesmo na distância, são afetados por outros sentidos na produção de outra educação. São encontros.

${ }^{10}$ A poesia é um jogo em que, sob a realidade aparente, aparece outra de repente.

Educação \& Formação, Fortaleza, v. 3, n. 7, p. 85-103, jan./abr. 2018

DOI: http://dx.doi.org/

http://seer.uece.br/redufor 
Encontros que potencializam zonas. É nesse entremeio, nesse entre, nesse encontro (virtual) dos corpos, que o cuidado brota, que o cuidado age. É na intensidade da tinta, do desenho, do objeto, que os corpos são afetados e produzem potências de ser, de existir. É no encontro que os sensos, os contrassensos, as silhuetas, se colocam em jogo. É na zona poética do cuidado que os sentidos brotam pelo meio.

Trata-se de uma política de trânsito por pormenores de formação em que os olhares se deixam capturar e se direcionam para as minúcias daquilo que acontece quando os sujeitos educandos e educadores - se encontram nessa zona de contágio, experimentando as territorialidades da escola. Assim, somando-se e dividindo-se, constituem ao mesmo tempo em que se constituem.

Dessa forma, ao propor o "enveredar" por uma zona do sensível, de afectos, de contágios, de experimentações (des)territoriais do cuidado, produziram-se zonas poéticas de cuidado nos encontros dos corpos que jogam sentidos e contrassensos. Proporcionando encontros de corpos, agenciando as produções de cuidado, transformando corpos em poemas, ajudou-se os educandos a experimentar o silêncio, o intervalo, o hiato que brota nos encontros, nos espaços vazios, nas trocas realizadas presencialmente e a distância.

Assim, pela escrita, desenvolveu-se em cada sujeito uma "viagem", de dentro para fora e de fora para dentro, em que, ao ler-se uma poesia, se conhecia um pouco mais de si. Ao produzir-se uma poesia, demonstrava-se um pouco mais do nosso "eu", que ao ser lido pelo outro ganhava a possibilidade de evoluir cada vez mais, aproximando-se da máxima goethiniana apontada no Wilhelm Meister:

[...] via pela primeira vez sua imagem fora de si mesmo, mas não como num espelho, um segundo eu, e sim como outro eu num retrato e sobre isso chegou a seguinte compreensão: não nos reconhecemos certamente em todos os traços, mas nos regozijamos que um espírito ponderado nos tenha percebido daquele modo, que um grande talento tenha querido representar-nos daquele modo, que uma imagem daquilo que fomos ainda subsiste e possa durar mais que nós mesmos. (GOETHE, 2006, p. 481-482).

Com isso, é possível apontar que a escrita, além de proporcionar a omnicompreensão, pode ser potencializadora de um crescimento contínuo dos indivíduos, quebrando narcisismos, esfacelando individualismos e possibilitando um novo olhar: um olhar de cuidado, para si e para com o outro. 


\section{PARA FINALIZAR... MAS NÃO ACABAR}

O Projeto Zonas Entre Nós, ao trabalhar a poesia como instrumento de recuperação do cuidado de si, problematiza, por meio das formas de expressão e dos exercícios com a poesia, projetos escolares em zonas de contato e aproximação da escola básica com a universidade, referenciando-se uma experiência desenvolvida no Ensino Fundamental e no Ensino Superior. Tal experiência possibilitou aos educandos o conhecimento, a criação e a expressão do mundo e de si, tendo como consequência vivências estéticas capazes de desconstruir a palavra, a imagem, as subjetividades e as formas/modos de aprender.

Resgatam-se, ainda, as muitas dificuldades encontradas por educadores para formar indivíduos frente a uma época de sociedade individualista, narcisista e hedonista. Com coragem, aponta-se a necessidade de resgatar - antes de outros aspectos - a omnicompreensão.

Como menciona Vidor (1996, p. 12), "se o homem não aprender a usar-se por inteiro não poderá pretender autoconhecer-se, autorregular-se, autoconduzir-se e autodefinir-se corretamente". Assim sendo, se o indivíduo não se conhecer por inteiro ou não se conhecer minimamente, de pouco ou quase nada adiantarão seu aprendizado e sua formação - menos ainda se esta for uma semiformação.

Não de forma conclusiva, mas provocativa, reforça-se - considerando-se que esta palavra seja a correta quando se lembra que a escrita sempre foi uma forma de formação, desde a Grécia antiga - que a escrita se coloca como uma grande ferramenta de autocompreensão, de evolução individual e coletiva. Mais ainda, como forma de escrita, por sua permissividade de expressão, a poesia coloca-se como uma excelente ferramenta de formação, seja em ambientes formais ou não, possibilitando o sair de si, a viagem formativa (como Bildung), a dialética da transformação interior. Fica, então, o desafio de ampliar e aprofundar o uso dessa ferramenta.

\section{REFERÊNCIAS}

ARISTÓTELES. Poética. Porto Alegre: Globo, 1966.

BROSSA, J. Poesia vista. São Paulo: Amauta, 2005.

Educação \& Formação, Fortaleza, v. 3, n. 7, p. 85-103, jan./abr. 2018

DOI: http://dx.doi.org/

http://seer.uece.br/redufor 
DELEUZE, G. Foucault. Lisboa: 70, 2005.

DELEUZE, G. Lógica da sensação. Rio de Janeiro: Jorge Zahar, 2007.

DIDI-HUBERMAN, G. A sobrevivência dos vaga-lumes. Belo Horizonte: UFMG, 2011.

FOUCAULT, M. Ética, sexualidade e política. Rio de Janeiro: Forense Universitária, 2004.

FOUCAULT, M. Estética: literatura e pintura, música e cinema. Rio de Janeiro: Forense Universitária, 2013.

FOUCAULT, M. História e Sexualidade 3: o cuidado de si. Rio de Janeiro: Graal, 1985.

FOUCAULT, M. Tecnologías del yo y otros textos. Barcelona: Paidós Ibérica, 1990.

GALLO, S. Cuidar de si e cuidar do outro: implicações éticas para a educação dos últimos escritos de Foucault. In: KOHAN, W. (Ed.). Foucault 80 anos. Belo Horizonte: Autêntica, 2006. p. 177-189.

GOETHE, J. W. Os anos de aprendizagem de Wilhelm Meister. São Paulo: 34, 2006.

GROS, F. O cuidado de si em Michel Foucault. In: RAGO, M.; VEIGA-NETO, A. (Ed.). Figuras de Foucault. Belo Horizonte: Autêntica, 2008. p. 127-138.

HAVELOCK, E. A. A revolução da escrita na Grécia e suas consequências culturais. São Paulo: Unesp: Paz e Terra, 1996.

HENZ, C. I.; ROSSATO, R. (Coord.). Educação humanizadora na sociedade globalizada. Santa Maria: Biblos, 2007.

JAEGER, W. Paideia: a formação do homem grego. São Paulo: Martins Fontes, 1994.

MARANGON, M. L. Goethe e a educação: princípios formação a partir da obra os Anos de Aprendizado de Wilhelm Meister. In: SIMPÓSIO DE ESTÉTICA E FILOSOFIA DA MÚSICA. 2., 2016, Porto Alegre. Anais... Porto Alegre: Sefim, 2016. p. 452-453.

MARCELLO, F. A.; FISCHER, R. M. B. Cuidar de si, dizer a verdade: arte, pensamento e ética do sujeito. Pró-Posições, Caminas, v. 25, n. 2, p. 157-175, 2014.

MARCONDES FILHO, C. Televisão: a vida pelo vídeo. São Paulo: Moderna, 1988.

MOREY, M. La cuestión del método. In: FOUCAULT, F. Tecnologías del yo y otros textos. Barcelona: Paidós Ibérica, 1990. p. 9-44.

PLATÃO. A república. 11. ed. Lisboa: Calouste Gulbenkian, 2008.

Educação \& Formação, Fortaleza, v. 3, n. 7, p. 85-103, jan./abr. 2018

DOI: http://dx.doi.org/

http://seer.uece.br/redufor 
PRECIOSA, R. Rumores discretos da subjetividade. Porto Alegre: Sulina: UFRGS, 2010.

REVEL, J. Foucault: conceitos essenciais. São Carlos: Claraluz, 2005.

RODRIGUES, E.; GAI, D. N. Parafernálias, cuidado, educação especial, saúde mental, literatura e etcéteras. In: SEMINÁRIO BRASILEIRO DE ESTUDOS CULTURAIS E EDUCAÇÃO. 6., 2015, Canoas. Anais... Canoas: SBECE, 2015. p. 1-13.

SCHULER, B. Por entre escritas, leituras e cadeiras: o procedimento genealógico e o cuidado de si. In: SCHULER, B.; MATOS, S. R. L.; CORAZZA, S. M. (Org.). Caderno de notas 6: experimentações de escrita, leitura e imagem na escola. Porto Alegre: UFRGS, 2014. p. 69-123.

TADEU, T.; CORRAZA, S.; ZORDAN, P. Linhas de escrita. Belo Horizonte: Autêntica, 2004.

TERÇA-NADA, M. Joan Brossa: pequeno panorama sobre sua vida e obra. 2003. Disponível em: <http:/marcelonada.redezero.org/artigos/joan-brossa.html>. Acesso em: 20 dez. 2016.

VEIGA-NETO, A. Foucault \& a Educação. Belo Horizonte: Autêntica, 2014.

VIDOR, A. A epistemologia interdisciplinar: o homem e seu conhecimento. Santa Maria: CE: UFSM: Pallotti, 1996.

Recebido em 24 de julho de 2017.

Aceito em 10 de fevereiro de 2018. 